\title{
Outbreak of Shiga toxin-producing E. coli O157 associated with consumption of watercress, United Kingdom, August to September 2013
}

\author{
N Launders (naomi.launders@phe.gov.uk) ${ }^{1}$, L Byrne ${ }^{1}$, N Adams ${ }^{1}$, K Glen ${ }^{1}$, C Jenkins ${ }^{2}$, D Tubin-Delic ${ }^{3}$, M Locking $^{4}$, C Williams ${ }^{5}$, D \\ Morgan ${ }^{1}$, on behalf of the Outbreak Control Team \\ 1. Gastrointestinal, Emerging and Zoonotic Infections Department, Public Health England, London, United Kingdom \\ 2. Gastrointestinal Bacteria Reference Unit, Public Health England, London, United Kingdom \\ 3. Incidents Branch, Food Standards Agency, London, United Kingdom \\ 4. Gastrointestinal and Zoonoses team, Health Protection Scotland, Glasgow, United Kingdom \\ 5. Health Protection Division, Public Health Wales, Cardiff, United Kingdom
}

Citation style for this article:

Launders N, Byrne L, Adams N, Glen K, Jenkins C, Tubin-Delic D, Locking M, Williams C, Morgan D, on behalf of the Outbreak Control Team. Outbreak of Shiga toxinproducing E. coli O157 associated with consumption of watercress, United Kingdom, August to September 2013. Euro Surveill. 2013;18(44):pii=20624. Available online: http://www.eurosurveillance.org/ViewArticle.aspx?Articleld=20624

An increase in the number of cases of Shiga toxinproducing Escherichia coli 0157 PT 2 stx2 infection was reported in the United Kingdom on 9 September 2013. Of the 19 cases, 13 were interviewed, of which 10 reported consuming watercress purchased from one retailer. The retailer recalled pre-packed bagged salads containing watercress on 12 September. The descriptive epidemiology was supported by a casecase study performed after control measures were implemented.

On 9 September 2013, the Public Health England (PHE) automated outbreak detection system [1] highlighted an increase in the number of cases of Shiga toxinproducing Escherichia coli (STEC) serotype 0157, phage type (PT) 2, Shiga toxin type 2 (stx2), which had been reported through the PHE Gastrointestinal Bacteria Reference Unit, London. During the week commencing 2 September, 12 cases were reported, compared with around one to two cases per week in the preceding months. Routine analyses of multiple-locus variablenumber of tandem repeats analysis (MLVA) profiles identified that the STEC isolates in 10 cases shared an identical or single-locus variant (SLV) MLVA profile (the outbreak profile), all reported in England since 30 August. The outbreak strain was intimin (eae) positive and haemolysin (hylA) positive.

\section{Background and descriptive epidemiology}

Routine enhanced surveillance of STEC has been in place in England since 1 January 2009. The STEC Enhanced Surveillance system (SESSy) combines detailed clinical and epidemiological data collected on enhanced surveillance questionnaires with microbiological characterisation of strains. Faecal samples from patients suspected to have STEC or haemolytic uraemic syndrome (HUS) are sent to local hospital laboratories where they are cultured for the presence of E. coli 0157 , then sent to the Gastrointestinal Bacteria Reference Unit for further characterisation. The local laboratories report presumptive isolates of STEC directly to PHE centres, who then arrange for the STEC Enhanced Surveillance Questionnaire (ESQ) to be administered. Contacts of cases that are deemed to pose a risk of onward transmission are screened, as are symptomatic contacts. The PHE Gastrointestinal Bacteria Reference Unit undertakes routine characterisation of isolates in England and Wales, while the Scottish E. coli 0157/VTEC Reference Laboratory, Glasgow, does so for cases in Scotland. Characterisation includes serogroup, phage and stx typing and MLVA for all STEC 0157 isolates.

STEC 0157 PT 2 is the fourth most common STEC phage type reported in England, with an average of 44 cases reported per year between 2009 and 2012, with a peak of cases in the summer months (unpublished data). Between 30 August and 19 September 2013, 18 cases of STEC 0157 PT 2 stx2 of the outbreak MLVA profile were reported in England $(n=14)$ and Wales $(n=4)$. Health Protection Scotland and the Scottish E. coli 0157/VTEC Reference Laboratory, Glasgow, were notified of the increase seen in England and Wales and identified one case in Scotland with the outbreak profile. Of the 19 reported cases, 17 were symptomatic primary cases; one was a symptomatic secondary case in the same household as a primary case, and one was an asymptomatic household contact of a primary case identified through contact screening. Symptom onset dates of the primary cases ranged from 17 to 29 August (Figure 1). Primary cases had an unusual demography for cases of STEC infection: they were predominantly female (11/17) (Figure 2), with a median age of 65 years (range: 4-87), whereas the highest incidence of cases in the UK are in children under the age of four $[2,3]$ Cases were geographically dispersed across the United Kingdom (UK). One case reported foreign travel in the 


\section{FIGURE 1}

Confirmed primary cases infected with STEC O157 PT 2 stx 2 of the outbreak MLVA profile, by date of symptom onset, United Kingdom, 17-29 August 2013 ( $\mathrm{n}=17$ )

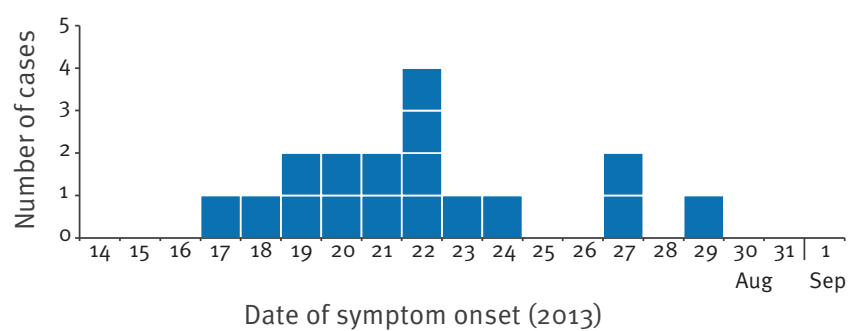

MLVA: multiple-locus variable-number of tandem repeats analysis; PT: phage type; STEC: Shiga toxin-producing Escherichia coli; STX: Shiga toxin.

seven days prior to symptom onset but UK acquisition could not be excluded. Seven cases were hospitalised, and 14 of the 18 symptomatic cases reported bloody diarrhoea, although no deaths or cases of HUS were reported.

\section{Hypothesis generation}

On 9 September, data collected through SESSy for England were reviewed for the 10 outbreak cases. The cases did not report any common travel destinations, or animal or environmental exposures. Scrutiny of the cases' food consumption histories revealed no plausible commonalities with the exception of pre-packed salad, which was reported by 9 of the 10 cases. Three cases specified watercress consumption.

On 10 September, a trawling questionnaire focusing on salad consumption was designed and four cases interviewed. Three of these cases reported consuming watercress bought from a major British retailer, Retailer A. This lead to the null hypothesis that infection with the outbreak strain was not associated with the consumption of watercress.

\section{Case-case study}

On 11 September, a case-case study was designed, comparing outbreak cases with cases of other enteric disease, to test the null hypothesis. Outbreak cases for the study were primary symptomatic cases infected with the outbreak strain confirmed by the Gastrointestinal Bacteria Reference Unit, over the age of one year and resident in the UK, with onset of symptoms on or after 17 August 2013. Reference-cases were primary indigenous symptomatic cases of Salmonella infection confirmed by the Gastrointestinal Bacteria Reference Unit, over the age of one year and resident in the UK, with onset of symptoms on or after 17 August
2013. Reference-cases were excluded if they were part of recognised outbreaks. Outbreak cases and reference-cases were matched by age group. One reference-case was allocated per outbreak case. Outbreak cases were contacted prior to contacting referencecases, to ascertain food history and aid trace-back investigations.

\section{Descriptive evidence}

Nine outbreak cases were interviewed by telephone using the case-case study questionnaire on 11 September. In total, 10 of the 13 cases interviewed either through trawling (3/4) or the case-case study (7/9) reported consumption of watercress bought from Retailer A, compared with an estimated background watercress consumption of approximately $4 \%$ for adults [4-8]. The seven cases interviewed using the case-case study questionnaire who consumed watercress reported that it was pre-packaged, washed and ready to eat.

\section{Control measures}

On 12 September, the Outbreak Control Team agreed that the descriptive epidemiological evidence was highly suggestive that watercress from Retailer A was the vehicle of infection and the Foods Standards Agency advised Retailer A to initiate a recall of watercress products. As a precautionary measure, Retailer A recalled six pre-packed bagged salads containing watercress on the afternoon of 12 September.

\section{Food chain and environmental investigation} The Food Standards Agency's food chain investigations identified the supplier and watercress farms that provided all the watercress to Retailer A during August 2013. During that time, Supplier A sourced watercress

\section{FIGURE 2}

Age and sex distribution of confirmed primary cases infected with STEC O157 PT 2 stx 2 of the outbreak MLVA profile, United Kingdom, August-September 2013 ( $\mathrm{n}=17)$

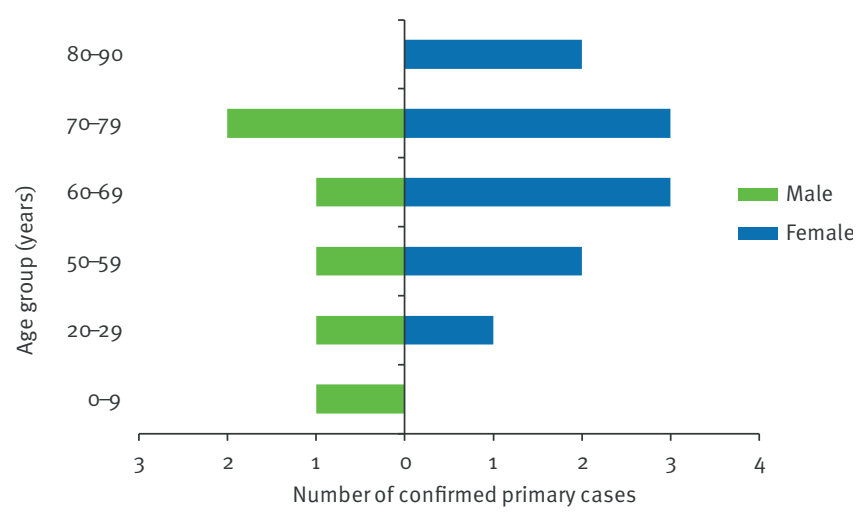

MLVA: multiple-locus variable-number of tandem repeats analysis; PT: phage type; STEC: Shiga toxin-producing Escherichia coli; STX: Shiga toxin. 
Single variable and multivariable analysis of odds of infection with STEC O157 PT 2 stx2 of the outbreak MLVA profile, United Kingdom, September $2013(n=22)^{a}$

\begin{tabular}{|c|c|c|c|c|c|c|c|c|c|c|}
\hline \multirow[b]{2}{*}{ Variable } & \multicolumn{2}{|c|}{ Outbreak cases } & \multicolumn{2}{|c|}{ Reference-cases } & \multicolumn{3}{|c|}{ Single variable analysis } & \multicolumn{3}{|c|}{ Multivariable analysis } \\
\hline & $\begin{array}{l}\text { Number } \\
\text { exposed }\end{array}$ & $\begin{array}{c}\text { Number } \\
\text { unexposed }\end{array}$ & $\begin{array}{l}\text { Number } \\
\text { exposed }\end{array}$ & $\begin{array}{c}\text { Number } \\
\text { unexposed }\end{array}$ & OR & $95 \% \mathrm{Cl}$ & P value & OR & $95 \% \mathrm{Cl}$ & P value \\
\hline \multicolumn{11}{|c|}{ Consumption of: } \\
\hline watercress & 10 & 1 & 1 & 10 & 100 & $6.74-\infty$ & 0.000 & 22.7 & $1.38-1,414.94$ & 0.025 \\
\hline tomatoes & 10 & 1 & 5 & 6 & 12 & $1.36-\infty$ & 0.022 & - & - & - \\
\hline yoghurt & 8 & 3 & 4 & 7 & 4.67 & $0.81-26.69$ & 0.087 & - & - & - \\
\hline \multicolumn{11}{|c|}{ Shopping at: } \\
\hline Retailer A & 9 & 2 & 2 & 9 & 20.25 & $2.55-161.09$ & 0.003 & 4.5 & $0.06-363.24$ & 0.66 \\
\hline
\end{tabular}

$\mathrm{Cl}$ : confidence interval; MLVA: multiple-locus variable-number of tandem repeats analysis; OR: odds ratio; PT: phage type; STEC: Shiga toxinproducing Escherichia coli; STX: Shiga toxin.

a Comprised 11 outbreak cases and 11 reference-cases.

for Retailer A from 10 farms in southern England. The 10 farms and Supplier A have detailed hazard analysis and critical control points (HACCP) plans. While some of the farms have livestock nearby, the watercress is protected from the ingress of livestock and surface water. The water flowing through the watercress beds is deep groundwater of a good microbial quality. Regular microbiological testing (coliform counts) is carried out on the water and pre- and post-packed watercress and all results for 2013 have been satisfactory to date. Samples of watercress from the field and following processing, as well as environmental samples, have been taken by local enforcement authorities at Supplier A's premises to help pinpoint the cause of the contamination. Further investigations into the supply chain of peat and the watercress seeds used by Supplier A are under way.

\section{Further epidemiological investigation}

As of 16 September, food histories were obtained for all 17 primary symptomatic cases: from enhanced surveillance questionnaires $(n=2)$, trawling questionnaires $(n=4)$ and case-case study questionnaires $(n=11)$. Of the 17 cases, 15 reported watercress consumption, of whom 13 had purchased the watercress from Retailer A.

\section{Case-case study results}

Reference-cases for the case-case study were contacted between 19 and 25 September. Data were imported into STATA for analysis. Variables that had a significant association with infection with the outbreak strain of STEC (odds ratio (OR) >1 and p<0.1) in single variable analysis were included in multivariable analysis. Unmatched multivariable analysis was performed using a binomial generalised linear model and exact logistic regression.

A total of 11 cases and 11 reference-cases were interviewed by telephone. The mean age of cases was 57 years (standard deviation (SD): 24.08) compared with 55 years (SD: 19.67) in reference-cases. Age and sex had no significant association with being an outbreak case in either single variable or multivariable analysis.

In single variable analysis, outbreak cases were significantly more likely to have consumed watercress, tomatoes and yoghurt, and have shopped at Retailer A than reference cases (Table). In multivariable analysis, consumption of tomatoes was excluded from the final model as it showed a protective effect that was not significant. Yoghurt consumption was excluded as while a significant association was shown, investigations showed multiple types of yoghurt, with no common ingredients, were consumed and it was therefore not a biologically plausible vehicle of infection.

In the final multivariable model, outbreak cases were significantly more likely to have consumed watercress than reference cases (OR: 22.7; 95\% confidence interval (CI): $1.38-1,414.94 ; p=0.025)$, but there was no significant difference between outbreak cases and reference-cases regarding shopping at retailer A (OR: 4.5; 95\% Cl: 0.06-363.24; $p=0.66$ ) (Table).

\section{Discussion}

This outbreak investigation provided strong descriptive epidemiology suggesting the likely vehicle of infection was bagged washed watercress from a specific retailer. Watercress is a well-recognised vehicle of transmission for fascioliasis in many countries [9-13] and a study of microbial contamination of pre-harvest watercress in New Zealand found high levels of E. coli and Campylobacter in watercress and growing water [14]. A case-control study of over 350 cases of STEC infection reported in England from 1996 to 1997 identified watercress as a risk factor for STEC infection [15]; however, as far as we are aware, this is the first known outbreak of STEC infection associated with watercress. 
Control measures were put in place before the casecase study was completed, illustrating that control action may be warranted on strong descriptive epidemiology alone, when supported by microbiological typing. The case-case study supported the descriptive findings, rejecting the null hypothesis that watercress was not associated with infection with the outbreak strain. Cases of the outbreak profile of STEC had increased odds of consuming watercress, though the confidence intervals were wide.

The analytical study had several limitations: the small sample size and the low power of the study, since only one reference-case was recruited per outbreak case. No association was found between infection with the outbreak strain of STEC and Retailer A, probably due to the market share of this retailer, and aforementioned limitations. While no cases of HUS were reported, seven cases were hospitalised and 14/18 reported bloody diarrhoea, suggesting that the outbreak strain did not cause only mild illness. The absence of HUS cases is probably due to the age of the outbreak cases. HUS following STEC infection is predominantly seen in young children [3]: only one case under the age of 10 years was reported in this outbreak.

Outbreaks of STEC infection have previously been associated with salad vegetables, such as spinach $[16,17]$. Ready-to-eat salad vegetables are vulnerable to contamination with pathogens at the pre-harvest level [18] and have been associated with many outbreaks of food-borne infections [10,16,17,19-23]. While salad vegetables labelled as 'washed' may instil confidence in the consumer, current methods for washing and decontaminating produce cannot guarantee that pathogens, if present, will be removed. It has been demonstrated that STEC can adhere to leaves and become internalised within leafy vegetables $[24,25]$. The application of controls to minimise the risk of faecal contamination during growing, handling and processing is therefore of fundamental importance in ensuring the safety of fresh produce [26].The STEC Enhanced Surveillance system for England provided invaluable information on potential vehicles of infection in this outbreak, and allowed for rapid production of a hypothesis as to the cause of the outbreak. This was aided by the nature of watercress consumption in the UK: a low proportion of the UK population are thought to consume watercress, but interviewed cases had good recall of eating the product. Interdisciplinary collaboration and cooperation from a major food retailer meant the implicated product was removed from the shelves within 72 hours of the outbreak being notified.

The recall of watercress from Retailer A was well publicised and received media attention, but did not result in the reporting of further cases. The latest date of onset in this outbreak was 29 August 2013, suggesting that the outbreak is over. However, investigations on the identified watercress farms are still ongoing and the source contamination is currently unclear. Possible routes of contamination of the watercress include a failure in control measures protecting the watercress from agricultural run-off, contamination of water or growing materials used in watercress production or contaminated watercress seeds. While the implicated watercress is a UK product and no cases are known outside the UK, until the source of the contamination is identified, the international implications are unclear. The international community should be aware of this novel vehicle of infection for STEC and also be vigilant for cases linked to this outbreak. It is known that watercress seeds are traded internationally, and so if contaminated, there is the potential for cases to occur outside the UK.

\section{Acknowledgements}

Written on behalf of the Outbreak Control Team. With thanks to local Public Health England centres and Local Authorities for their assistance in the investigation of cases, to John Harris for his analysis of the analytical study, and to Dr Michael Wright and Vivienne do Nascimento for laboratory investigations.

Conflict of interest

None declared.

\section{Authors' contributions}

Naomi Launders: Outbreak management, hypothesis generation, study design, data analysis, writing of manuscript. Lisa Byrne: Case identification, hypothesis generation, data analysis, liaison with laboratory staff. Natalie Adams: Data collection and study protocol review. Kirsten Glen: Data collection. Claire Jenkins: Interpretation of typing and MultiLocus Variable-Number Tandem Repeat Analysis (MLVA). Drazenka Tubin-Delic: Trace-back investigation and provision of food consumption data, communication with retailer, coordination of environmental investigations. Mary Locking: Coordination of Scottish cases, data and response. Chris Williams: Coordination of Welsh cases, data and response. Dilys Morgan: Outbreak lead and chair of the outbreak control team. 


\section{References}

1. Farrington $C P$, Andrews NJ, Beale AD, Catchpole MA. A statistical algorithm for the early detection of outbreaks of infectious disease. J R Statist Soc A. 1996;159(3):547-63. http://dx.doi.org/10.2307/2983331

2. Willshaw GA, Cheasty T, Smith HR, O’Brien SJ, Adak GK. Verocytotoxin-producing Escherichia coli (VTEC) $0_{157}$ and other VTEC from human infections in England and Wales: 19951998. J Med Microbiol. 2001;50(2):135-42. PMid:11211220.

3. Thomas A, Cheasty T, Frost JA, Chart H, Smith HR, Rowe B. Vero cytotoxin-producing Escherichia coli, particularly serogroup 0157, associated with human infections in England and Wales: 1992-4. Epidemiol Infect. 1996;117(1):1-10. PMid:8760944. PMCid:PMC2271662.

4. Finch S, Doyle W, Lowe C, Bates CJ, Prentice A, Smithers G, et al. National diet and nutrition survey: people aged 65 years and over. Volume 1: Report of the diet and nutrition survey. London: The Stationery Office; 1998.

5. Gregory JR, Collins DL, Davies PSW, Hughes JM, Clarke PC. National diet and nutrition survey: children Aged 1 1/2 to 4 $1 / 2$ years. Volume 1 : Report of the diet and nutrition survey. London: Her Majesty's Stationery Office; 1995.

6. Gregory J, Lowe S, Bates CJ, Prentice A, Jackson LV, Smithers G, et al. National diet and nutrition survey: young people aged 4 to 18 years. Volume 1: Report of the diet and nutrition survey. London: The Stationery Office; 2000.

7. Henderson L, Gregory J, Swan G. National diet and nutrition survey: adults aged 19 to 64 years. Volume 1: Types and quantities of foods consumed. London: The Stationery Office; 2002. PMid:15062169.

8. Ministry of Agriculture Fisheries and Food (MAFF). Dietary survey of vegetarians: Final technical report. Research and development and surveillance report: 181. MAFF; 1996.

9. Ashton WL, Boardman PL, D'Sa CJ, Everall PH, Houghton AW. Human fascioliasis in Shropshire. Br Med J. 1970;3(5721):500 2.

http://dx.doi.org/10.1136/bmj.3.5721.500. PMid:4195344. PMCid:PMC1701344.

10. Dauchy FA, Vincendeau P, Lifermann F. Eight cases of fascioliasis: clinical and microbiological features. Med Mal Infect. 2006;36(1):42-6. http://dx.doi.org/10.1016/j.medmal.2005.10.005. PMid:16309872.

11. Fica A, Dabanch J, Farias C, Castro M, Jercic MI, Weitzel T. Acute fascioliasis--clinical and epidemiological features of four patients in Chile. Clin Microbiol Infect. 2012;18(1):91-6. http://dx.doi.org/10.1111/j.1469-0691.2011.03575.x. PMid:21668579.

12. Mera y Sierra R, Agramunt VH, Cuervo P, Mas-Coma S. Human fascioliasis in Argentina: retrospective overview, critical analysis and baseline for future research. Parasit Vectors. 2011;4:104.

http://dx.doi.org/10.1186/1756-3305-4-104. PMid:21663691. PMCid:PMC3141741.

13. Sripa B, Kaewkes S, Intapan PM, Maleewong W, Brindley PJ. Food-borne trematodiases in Southeast Asia epidemiology, pathology, clinical manifestation and control. Adv Parasitol. 2010;72:305-50 http://dx.doi.org/10.1016/So065-308X(10)72011-X

14. Edmonds C, Hawke R. Microbiological and metal contamination of watercress in the Wellington region, New Zealand--2000 survey. Aust N Z J Public Health. 2004;28(1):20-6. http://dx.doi.org/10.1111/j.1467-842X.2004.tboo627.x

15. O'Brien SJ, Adak GK, Gilham C. Contact with farming environment as a major risk factor for Shiga toxin (Vero cytotoxin)-producing Escherichia coli 0157 infection in humans. Emerg Infect Dis. 2001;7(6):1049-51. http://dx.doi.org/10.3201/eido706.010626. PMid:11747741. PMCid:PMC2631906.

16. Grant J, Wendelboe AM, Wendel A, Jepson B, Torres P, Smelser C, et al. Spinach-associated Escherichia coli $0_{157}: \mathrm{H}_{7}$ outbreak, Utah and New Mexico, 2006. Emerg Infect Dis. 2008;14(10):1633-6.

http://dx.doi.org/10.3201/eid1410.071341. PMid:18826833. PMCid:PMC 2609868.

17. Wendel AM, Johnson DH, Sharapov U, Grant J, Archer JR, Monson T, et al. Multistate outbreak of Escherichia coli 0157: $\mathrm{H} 7$ infection associated with consumption of packaged spinach, August-September 2006: the Wisconsin investigation. Clin Infect Dis. 2009;48(8):1079-86. http://dx.doi.org/10.1086/597399. PMid:19265476.

18. Park S, Szonyi B, Gautam R, Nightingale K, Anciso J, Ivanek R. Risk factors for microbial contamination in fruits and vegetables at the preharvest level: a systematic review. J Food Prot. 2012;75(11):2055-81.
http://dx.doi.org/10.4315/0362-028X.JFP-12-16o. PMid:23127717.

19. Decraene V, Lebbad M, Botero-Kleiven S, Gustavsson AM, Löfdahl M. First reported foodborne outbreak associated with microsporidia, Sweden, October 2009. Epidemiol Infect. 2012;140(3):519-27.

http://dx.doi.org/10.1017/S095026881100077X. PMid:21733266. PMCid:PMC3267097.

20. Gobin M, Launders N, Lane C, Kafatos G, Adak B. National outbreak of Salmonella Java phage type 3 b variant 9 infection using parallel case-control and case-case study designs, United Kingdom, July to October 2010. Euro Surveill. 2011;16(47):pii=20023. Available from: http://www. eurosurveillance.org/ViewArticle.aspx?Articleld=20023. PMid:22152706.

21. Little CL, Gillespie IA. Prepared salads and public health. J Appl Microbiol. 2008;105(6):1729-43 http://dx.doi.org/10.1111/j.1365-2672.2008.03801.x. PMid:18397258.

22. MacDonald E, Heier BT, Nygård K, Stalheim T, Cudjoe KS, Skjerdal T, et al. Yersinia enterocolitica outbreak associated with ready-to-eat salad mix, Norway, 2011. Emerg Infect Dis. 2012;18(9):1496-9. http://dx.doi.org/10.3201/eid1809.120087. PMid:22932318. PMCid:PMC3437701.

23. Nygård K, Lassen J, Vold L, Andersson Y, Fisher I, Löfdahl S, et al. Outbreak of Salmonella Thompson infections linked to imported rucola lettuce. Foodborne Pathog Dis. 2008;5(2):165-

h3.

24. Shaw RK, Berger CN, Feys B, Knutton S, Pallen MJ, Frankel G. Enterohemorrhagic Escherichia coli exploits EspA filaments for attachment to salad leaves. Appl Environ Microbiol. 2008;74(9):2908-14. http://dx.doi.org/10.1128/AEM.02704-07. PMid:18310437. PMCid:PMC2394865.

25. Xicohtencatl-Cortes J, Sánchez Chacón E, Salda-a Z, Freer E, Girón JA. Interaction of Escherichia coli $0_{157: H 7}$ with leafy green produce. J Food Prot. 2009;72(7):1531-7. PMid:19681282.

26. Monaghan J, Hutichison M. Monitoring microbial food safety of fresh produce. Horticultural Development Company and Food Standards Agency Factsheet (13/10). Kenilworth: Agriculture and Horticulture Development Board; 2010. Available from: http://www.food.gov.uk/multimedia/pdfs/microbial.pdf 